\title{
What Do Psychodynamic Therapists Make of their Reveries in the Therapeutic Encounter? A Constructivist Grounded Theory Study by Femke Stokes and
} Alistair Ross ${ }^{1}$

Sometimes the therapist's mind will wander to daydreams, fantasies and preoccupations: mental events termed 'reveries' in this study. The present study aims to investigate the thoughts, feelings, and attitudes therapists have about their reveries in relation to the therapeutic encounter with the patient, including whether reveries are felt to be clinically useful. Semi-structured interviews were conducted with nine qualified psychodynamic therapists. Data were analysed using a constructivist grounded theory methodology (Charmaz, 2014). The results of the study showed that therapists experience a diverse inner life of reverie in the therapeutic encounter, which they consider a fundamental component of psychodynamic work. In particular, reveries were considered to be an important countertransference phenomenon that can provide deeper clinical understanding. They were also seen as having a 'freeing-up' function for the therapist and patient. Reveries were additionally felt to require a certain degree of mental freedom to operate. The implications for theoretical understanding and recommendations for a clinical technique that includes attention to reverie are considered.

Keywords: reverie; fantasy; unconscious communication; countertransference; intersubjectivity

\footnotetext{
${ }^{1}$ Department for Continuing Education, University of Oxford
} 


\section{Introduction}

The therapist's mind and inner world are considered key tools in the practice of psychodynamic therapy. At times in a therapy session a therapist might spontaneously engage in reveries as their mind-wanders to a daydream, fantasy, or preoccupation. This qualitative study investigated what therapists make of their reveries in this context, and whether they attribute clinical value to them.

Ogden (1997) and others (Cwik, 2011; Mathew, 2005) use the term 'reverie' to encompass a variety of mental phenomena: primarily daydreams, fantasies and preoccupations. This definition goes beyond Bion's influential concept (1962b) of 'maternal reverie', although Bion's theory is relevant to this study. Importantly, this study aimed to elicit the language and definitions that research participants themselves bring to the phenomenon of 'reverie'.

Freud, recommended that the analyst try to 'surrender himself to his own unconscious mental activity, in a state of evenly suspended attention', in order 'to catch the drift of the patient's unconscious with his own unconscious' (1923a, p. 239). Ogden (1997, p. 81), takes up Freud's point and emphasizes the therapeutic usefulness of the analyst's tolerance of 'being adrift', carried by a 'current of reverie', which arises out of the interplay of the analyst and analysand's subjective states of mind, both conscious and unconscious (2002, p. 19).

An interest in the reveries of the therapist has grown following the 'relational turn' in psychoanalysis, in which the dynamic between therapist and patient has been formulated as intersubjective in nature (eg. Chodorow, 2004; Benjamin, 1995; Stolorow \& Atwood, 1992; Maroda, 1991). A number of relational psychoanalysts treat the therapist's reveries as a form of countertransference that may reveal 
unconscious communication from the patient (Vapenstad, 2014; Cooper, 2008; Ferro, 2009; Ogden, 2004, 1997; Vaslamatzis, 1999). These writers build on Bion's idea (1926b) of 'maternal reverie' in the service of the 'containment' of the baby's emotions, which facilitates the growth of the child's own capacity for thought. This has its counterpart in the work of reverie and containment performed by the therapist for the patient.

Several Jungian authors (Cwik, 2011; Mathew, 2005; Bovensiepen, 2002) add to Bion's notion of 'maternal reverie' by emphasizing the value of creativity in the therapeutic process through the use of fantasy, dreams and the healing function of 'active imagination' (Jung, 1925). Active imagination was for Jung the art of letting thoughts and images arise spontaneously in the psyche in a state of 'reverie halfway between sleeping and waking'(Stevens, 1990, p. 202). Bovensiepen (2002) and Cwik (2011) argue that the analyst can usefully combine 'maternal reverie' along Bionian lines with Jungian 'active imagination' to harvest symbols of the patient's experience. This is felt to open up a greater 'psychic space' for the patient through the intersubjective process of symbol formation that takes place between the analyst and the patient.

Overall, the psychoanalytic literature tends to value the therapist's reverie as a source of information about the patient's inner world and psychic life, including the transference-countertransference, and it suggests that reveries can be harnessed to enhance the therapeutic process. This theory warrants further exploration as it bears a highly significant implication for technique in psychotherapy involving the use of the therapist's reverie, if reverie can indeed be felt to impact the therapeutic process. The current study aims to assess the extent to which therapists believe that their reveries 
contribute to the therapeutic process, and to explore ways in which this is felt to happen.

The therapist's reveries can be usefully thought of in terms of what the field of cognitive neuroscience has termed 'spontaneous thought'. It includes such mental processes as daydreaming, mind-wandering and

thought processes that occur spontaneously and bear no relation to the task at hand.' (Christoff, Ream \& Gabrieli 2004, p. 624).

Cognitive neuroscientists (Andrews-Hanna, Reidler, Huang \& Buckner 2010; Buckner, Andrews-Hanna, \& Schacter 2008; Christoff, Ream, \& Gabrieli 2004) have established a neural basis for 'spontaneous thought', termed the 'default network'. Andrews-Hanna et al (2010, p. 323) described this as a set of brain regions that is activated during 'passive states' when 'spontaneous, internally directed cognition' takes over, as opposed to cognitive interaction with external stimuli. Christoff, Gordon, \& Smith (2009, p. 275; p.277) have argued that spontaneous thought is a particularly 'creative, associative' mode of cognition that 'comes from our intuitions and subjective introspections'.

Given findings that mind-wandering is a distinctive and normal mode of cognition with a distinct neural basis, it is useful to investigate what implications this might have for therapists relying on the use of their mind and internal world. The association of spontaneous thought with 'internally directed' 'intuitions and creative introspections' make it an apt mode of thought to examine within the psychotherapeutic context. 
There is little empirical research literature on the therapist's reverie. McGowan (2015) investigates the related topic of the therapist's spontaneous mental imagery and its effect on the therapeutic relationship. This qualitative study finds that spontaneous mental imagery is experienced as powerful and multi-sensory by the therapists, who felt that it informed and potentially transformed the therapeutic relationship. The therapist's spontaneous mental imagery might be considered a form of reverie. Our study sought to classify and explore what forms therapists' reveries took, with an interest in any mental events (including imagery) that arise in the therapist's mind.

Overall, there are a number of unanswered questions in the literature with regards to what reverie is and how it takes place. Our study aimed to use a qualitative investigation to explore how psychodynamic therapists experience and ascribe meaning to/evaluate their reveries, and how they might see implications for clinical technique. Specifically, the research questions framing the study were:

- What types of mental events do therapists experience during 'reveries'?

- What language do therapists use to conceptualise what in the literature is termed 'reveries'?

- What have therapists thought and felt about this kind of mental event, when it has ocurred, including the meaning (if any) they might attribute to it?

- How do therapists see their reveries in relation to the therapeutic encounter with the client?

- Do therapists feel their reveries can offer anything to the therapeutic process, and what, if so? 


\section{Method}

\section{Design}

Given the inductive, exploratory nature of the research, it was felt that a qualitative methodology was appropriate. In the absence of existing empirical literature, grounded-theory was chosen as the methodology (Charmaz, 2006, 2014), since this method begins with data and not with theory.

Specifically, a constructivist grounded theory methodology was adopted (Charmaz 2014) as this approach emphasizes the co-creation of meaning between researcher and participant, which was germane to the intersubjective context of the encounter between therapist and patient for the therapist's reveries. The discovery of meaning in the research topic under investigation is an interactive process shared by researcher and participant, each inevitably bringing their subjectivities to bear upon the interpretations that are developed together (Charmaz, 2014). The intensive process of the semi-structured interview provides the first intersubjective encounter. The researcher's analysis and account of the participants' narratives involve further encounters as the researcher engages with the data, and meaning is co-created.

Furthermore, constructivist grounded theory emphasizes paying attention to the meanings participants 'attribute to the process' under investigation Charmaz (2014, p. 20), rather than simply analyzing themes. Reverie (such as daydreaming and mindwandering) is a process and it was the aim of the study to investigate what psychodynamic therapists make of this process within the context of the clinical 
encounter.

Constructivist grounded theory particularly emphasizes that it is not that theories are discovered in the data, but rather that we as researchers 'construct our grounded theories through our past and present involvements and interactions with people, perspectives, and research practices' (Charmaz 2014, p. 17). It is a notable epistemological shift away from earlier positivist and objectivist forms of grounded theory, particularly Glaser \& Strauss (1967).

\section{Participants}

The sample consisted of nine participants (seven females, two males) including psychodynamic counsellors, psychoanalytic psychotherapists, and psychoanalysts of Kleinian \& British Independent, Jungian and Lacanian orientation.

Robson (1993) and Charmaz (2014) assert that purposive sampling is suitable for grounded theory as it enables the researcher to build up a sample in line with his/her judgement of typicality or expertise. Purposive sampling was used to find participants who were of a psychodynamic orientation because the concept of 'reverie' was approached in the study within a psychodynamic framework. However, 'psychodynamic therapy' is a broad church and so within this category breadth was permitted in the sample, including therapists of any psychoanalytic theoretical orientation, and practitioners qualified as counsellors, psychodynamic psychotherapists, psychoanalysts, and group analysts. It was felt that this heterogeneity within the well-defined category of 'psychodynamic practice' would enhance the study, taking it beyond the narrower confines of the purely psychoanalytic literature. Participants' experience ranged from four to thirty years. 
Participants worked in a variety of settings: the public sector, universities and private practice.

\section{Procedure}

Ethical approval was granted. I also adhered to Bond's (2004) Ethical Guidelines for Researching Counselling and Psychotherapy.

Semi-structured interviews (audio-recorded and transcribed verbatim) using open-ended questions were used to give participants as much freedom as possible. Although the phenomena being studied was termed 'reveries', the study sought to elicit the participant's own language, definitions and examples for these phenomena, in accordance with a constructivist stance (Charmaz 2006, 2014). The semi-structured interview is an intensive mode of gathering rich data that draws out the participant's interpretation of his/her experience as he/she is given the opportunity to explore it in depth (Charmaz, 2006, p. 25 ). The co-creation of meaning began to emerge in the interviews through the collaborative discussion of the researcher and each participant. In this way, data are constructed (Charmaz, 2014). To ensure reliability and validity throughout the study Yardley's (2000) criteria for qualitative research were followed.

\section{Analysis}

The data were subjected to analysis via two levels of coding: 'initial coding' and 'focused coding', before the final stage of analysis: theory building. Initial coding entailed descriptive line-by-line codes using gerunds (eg. 'Letting the mind roam free; 'Processing the reverie in the middle of the night') to code for actions/processes 
(Charmaz, 2014), using the participant's own words to generate the code to help anchor the developing theory to participants' perspectives. Focused coding is an analytic step up from initial coding, as it is used to 'sift, sort, synthesize and analyze large amounts of data', advancing the theoretical direction of the analysis (Charmaz, 2014, p. 138). Following the grounded theory principle of simultaneous data collection and analysis interview, questions were adapted as analysis generated new perspectives, some of which were followed up in susbsequent interviews. Questions about setting were added in, for example, as this theme came up in early interviews. Memos were used to record and explore analytic thinking about what was happening in the data. This is a form of journaling that assists the researcher in exploring ideas. Creating memos is an important component of grounded theory analysis that charts the development of the analysis and serves the construction of theoretical categories (Glaser \& Strauss, 1967; Charmaz, 2014). As the researcher's analytic mind was brought to bear upon the interview data, the co-creation of meaning between researcher and participants was further developed.

The final stage of the analysis was the building of the emergent theory. Following the grounded theory principle of 'constant comparison' (Glaser and Strauss, 1967), units of data and codes were compared and contrasted to identify commonalities and differences in order to check emerging theory against the data. Focused codes were clustered under the headings of theoretical categories, as patterns emerged. Lists and diagramming (cluster maps, made with pen and paper) were then used to experiment with the organization of categories, sustaining reflexivity throughout this process with the use of memos.

\section{Results}


Five principal categories emerged. These categories are process-orientated, capturing what participants made of their reveries at different stages of the experience of having a reverie, processing it, and thinking about its meaning and value.

(1) Going into a Reverie

Participants described how reveries unfold in the clinical encounter and identified various forms their reveries typically take, as well as the multiple mental processes that are felt to come into play.

\section{Letting your mind go}

Participants described entering a state of mind that is felt to be qualitatively different to usual ways of thinking: reverie was 'a retreat into some inner world'(E). Another described it as 'using my imagination to see into the dark' (D). A third participant explained that in a reverie 'you cast your mind into a different way of thinking' $(\mathrm{H})$.

Participants described noticing fragmentary reveries manifesting as 'associations, film clips, music, words, fragments of goodness knows what, whatever comes into my mind' (H). Some described much more developed, 'vivid', reveries, involving detailed scenes imagined from the patient's life, past or present.

Many participants compared entering a reverie to dreaming. Reveries were also seen as operating in a hinterland close to madness. Two participants (A, E) compared reveries to psychosis, noting similarities and differences, and a third said 
I think there's also something that I would call

hallucinatory ... there's something about the

daydreaming aspect of it, just letting one's mind go

wherever it needs to go, and then seeing what comes out

of that $(\mathrm{G})$.

Reveries occurring in and between sessions

Participants mentioned reveries in the clinical context occurring both in and between sessions. Participants described reveries in sessions as involving simultaneous mental presence and absence. Many participants described entering simultaneously into more than one kind of mental process during the experience of reverie within a session. Due to the 'mind-wandering' nature of reverie, it had a quality, for some participants, of simultaneous mental presence and absence:

So you're in a reverie, which by definition means you're not all there, but actually at the same time you're all there, cause your mind's focusing on one function' (A)

Several participants also described it in terms of conscious, and less conscious, processes:

I'm allowing myself to see [the clinical material] through something else in... in a memory or a daydream, because that's easier somehow for my mind to process both my 
countertransference feeling and also, more conscious thoughts of what's happening. (C).

The mental multi-tasking involved in entering into reverie in response to a patient emerged as a key experiential component of reverie occurring in sessions. It prompted one participant to comment that, 'It feels like you're trying to hold the baby but allow your thoughts to wander and have a mind of your own' (E). Here the relational quality of the process reverie is emphasized as the participant goes on to affirm: 'So for me it's a relational idea, so you're holding something, you're holding some attention, but you're allowing the mind to go elsewhere' (E).

Between Sessions:

Participants also gave examples of reveries unfolding between sessions, either in supervision, or in solitary moments. These are often experienced as sudden preoccupations with the patient. A number of patients mentioned that these reveries could occur during private moments. One participant referred to reveries of patients occurring when 'walking him [gestures at dog] round the park' $(\mathrm{G})$ and another mentioned reveries about patients in the bath:

And I may take a little [mimes a drink] up with me and lie there with my smelly oils and things. And start thinking about who I'm seeing tomorrow and then I just sink down in the bath and just let my mind roam free. (A) 
According to the data, reveries arising between the sessions often occur in private, intimate contexts for the therapist. The content of reveries experienced in the sessions, as described above, is often of a relational nature, sometimes romantic or sexual. This leads on to the next category:

(2) Experiencing a Relational Focus in Reveries

Participants often experienced a relational focus to the content of their reveries; they also tended to see their reveries as generated by dynamics of the therapeutic relationship itself.

\section{Relational content of reveries}

Therapists were finding themselves imagining what it is like to be another important member of the patient's life, or in a different kind of relationship with the patient: 'what would it be like to be [the patient's] sister or what it would like to be his lover, so I would fantasise, you know, daydream' (A). One participant described a fantasy that a 'prickly, defensive' patient 'was like Sleeping Beauty and she wanted me as the Prince to hack through the thicket fence'. (H) She reflected that the reverie symbolized the patient's defence against the intimacy of the therapeutic relationship, and her tendency to put the therapist off, so that the therapist was left asking 'Do I want to come anywhere near you?'.

Another participant described entering into a daydream involving the male partner in a couple therapy session: 
I suddenly had this vision, a visual thing of me and him, both of us very old, sitting on either side of a fireplace and me knitting in a rocking chair...you know, two old people growing old together' (A).

In analyzing this particular reverie, this participant felt that she was experiencing a transference to her own husband, and possibly father, and she emphasized the role of her own subjectivity in the reverie. It is nonetheless striking that all three of these reveries have a romantic aspect to the fantasised relationship with the patient. It raises questions about the relational dynamics influencing reveries. These might be conscious and unconscious and include erotic transference.

Seeing reveries as generated by the therapeutic relationship

Participants tended to see their reveries as a 'co-creation' (D) of the therapist and the patient: 'a kind of meeting of yourself and the patient in there' (B). The point was strongly made that reveries in the session can be unconsciously 'led by the patient' (F), via the relationship:

So it's what actually happens within the room or that actually the patient has evoked in me that would actually promote or facilitate that kind of reverie $(\mathrm{F})$. 
Many participants saw the therapist's task as receiving unconscious communication and processing it 'on behalf of the patient' $(\mathrm{C})$. One participant explained that in response to her reveries she would ask herself "what's the unconscious couple in the room up to?' $(\mathrm{H})$. Therapists tended to feel that their reveries can be an act of symbolizing a communication that the patient needs the therapist to receive, whether of certain feelings, or memories. One participant had a reverie of traumatic content that she felt intuited traumatic experience not yet recounted by the patient:

I felt the purpose was somebody needed to know and at this point I could know ... maybe there was something in [the patient] that thought 'Yes, I'm safe and now I can risk somebody knowing'. (H).

Another participant compared the dynamics of reverie to those of the mother-infant relationship, as she felt her reveries had a quality of 'timelessness' to them, and, she stated, 'I think I'd link that to the mother-baby experience of timelessness'. (C). In these diverse ways, participants described their reveries as arising within a relational matrix.

(3) Finding Reveries Require the Therapist's Mental Freedom

Participants characterised the therapist's reverie as freeing, both for therapist and patient: 'it brings a freedom and it brings space. So it's such a creative process' (B). 
Participants described ways of attaining the mental freedom requisite for reverie, and the extent to which they felt reverie itself has a freeing function. Participants commonly used a language of permission to describe this process:

You let your mind wander ... Let yourself go mad, in a way. (A)

So you're almost allowing yourself to get easily

distracted ... so it's a kind of allowing your imagination to roam a little bit. (E)

A number of participants specified that they needed to be able to shift their gaze, to find a point of departure to 'let [the] mind wander' in this way:

I have a rug that's a sort of a tapestry and I quite like looking down and... letting my imagination kind of, you know, take flight from there. (D).

I absolutely cannot work in a room without a window ... And I think that's something to do with me feeling opened and freed in my own self having a window ... A window into another world (C)

Inhibitions to Reverie 
Participants described impingements to this mental freedom. Some mentioned that brief work made it harder: 'how do I allow for space for a reverie? There's no time for that'. (C).

Patients' defences were felt to inhibit the therapist's reveries, especially those of obsessional patients. Describing his lack of reverie with an anorexic patient, one participant commented:

my mind goes blank, you know, nothing fills it ... She's not putting anything out that stirs anything really that sets that processing going. ... she's got these very rigid ways of dealing with her internal world (E)

Some participants working within organizations also specified that institutional stress can inhibit reveries:

if in the institution there's a lot of anger and there's a lot of stress around ... then I would be less inclined to be flexible enough to go into a reverie (B)

(4) Processing and Using Reverie: Privacy and Disclosure

The processes of thinking through of reveries and using them for possible clinical understanding and therapeutic change requires privacy, although sharing the reverie in 
supervision, and at times with the patient, was also felt by participants to be potentially helpful.

\section{Processing Reveries Privately}

A few participants mentioned the experience of processing a reverie about a patient 'in the middle of the night' or 'under the duvet'(C; A), which suggests the privacy and intimacy involved in processing reverie.

One participant found that giving herself time to privately let unconscious processes 'percolate' and then writing up notes helped her to process reveries: 'I will leave a gap of two or three days, if not more ... once I've had time for unconscious processes to go on within me.' (F).

Another participant spoke of the importance, for processing reveries, of 'the free association that you're letting yourself do in the privacy of your own home without an external supervisor present.' (A). She described this process as 'very, very, private' and said that it could enable her to 'hit on something' and furthermore, she felt, 'I wouldn't have hit on that in external supervision.' (A).

In this way, participants suggested that the processing of reverie could itself involve daydreaming and free association.

Sharing Reveries in Supervision 
It emerged strongly in the data that participants also value bringing their reveries (and having further reveries) in supervision:

There's a depth to the supervision, when you can do that together. There's depth and there's play and it's... something different that is actually being born in the transitional space, I think. (B).

Some participants who are themselves supervisors invite supervisees to bring reveries. They also said that they might themselves engage in reveries in response to hearing about the supervisee's patient, and to 'invite' the supervisee to engage in further reverie in supervision:

to sort of free associate, rather than just kind of giving an account of the last session’ (I).

Deciding whether to disclose a reverie to the patient

In discussing how they might use their reveries in the clinical context, participants did not always rule out disclosing the reverie to the patient, but they emphasized caution:

It always has elements from the patient and elements from yourself, and I suppose I'm quite cautious about sharing those reveries with the patient for that reason, really. (I) 
Participants also mentioned the importance of whether the patient is ready to hear the information conveyed in the reverie or to tolerate the intimacy involved in the disclosure, or whether it is 'too deep, too soon' (C). Sometimes, one participant mentioned, it is necessary to 'bin' the reverie, if it is felt to relate too much to the therapist, and not to the patient (A). Another participant made a similar point:

I think there has to be ... a differentiation, an attempt to
realise that actually my own feelings absolutely can
impact on the patient, and that's my stuff. It's not theirs. (G)

(5) Valuing Reveries as a Fundamental Component of Psychodynamic Work

Participants commonly stated that they felt the therapist's reverie was a fundamental component of psychodynamic therapy: as one participant stated, 'I couldn't do my work without reverie' (G).

Relating to Reverie as an Important Countertransference Phenomenon

When discussing the role and value of their reveries in their clinical work, participants felt reveries were a valuable type of countertransference. Some participants were explicit about this: 
I do think my reverie within a session is a really quite important part of the countertransference in its broadest sense, which might tell me something about the patient.

(I)

This concept emerged implicitly in the attitudes other participants took towards their reveries, feeling that reveries pointed to the patient's inner world:

by and large you trust that it has some relevance to the material, though you don't always realize it straight away. (E).

A number of participants expressed that their reveries can reveal something about the patient's attachment style and relational experiences in particular:

[the reverie] may just reveal the difficulties in attachment that my patient had as a baby, as a young child and... and possibly how that was damaged in some way... and how then that might be transferring to our relationship. (C)

Therapist's Reveries can be freeing for the patient

Participants valued their reveries as freeing up mental processes for the patient: 
the actual fact that I was able to have daydreams within the session ... allowed [the patient] to actually process thoughts, to be free to daydream, which she hadn't been allowed to do within her own maternal dyad. (F)

The point was also made that the therapist's reveries can help patients who are 'very self-critical about any wishes or any dreams that they might have'. (B)

Likewise, a number of participants felt that reveries assisted play in the therapeutic encounter: ' it can be kind of playing, as it were, in a kind of shared potential space between us' (I).

\section{Discussion: 'Holding the Baby But Having a Mind of Your Own'}

The analysis showed that psychodynamic therapists experience an extensive inner life of reverie in the therapeutic encounter, which they tend to value as an intrinsic part of their clinical work. Therapist's reveries were felt to involve the dual operation of attention/receptivity to the patient and the privacy/freedom of the therapist's own wandering mind. This resonates with Bion's 'maternal reverie' (1962b): the containing function of the mother's own independent mental apparatus and capacity to receive, process and symbolise her baby's raw feelings. It also evokes Winnicott's (1960) 'holding', which emphasizes the extent to which the mother 'feels herself into the infant's place' (1956, p. 304). Participants felt that their reveries could constitute an intuitive sensing of material in the patient's psyche. 
An interesting and novel finding was the extent to which participants strongly expressed the freeing function of their own reveries, both for themselves and potentially for their patients, too. The freedom to daydream allows an alternative to engaging in more linear, rational thinking. Participants seemed to experience needing to allow themselves to transgress certain mental boundaries in order to be able to dream in this way. This was felt to offer new possibilities for patients in terms of the growth and use of a psychic space in which to dream about themselves. This aspect was highlighted as a key way in which the therapist's reverie can be of therapeutic benefit. The prevalent association made by participants between their reveries and mental freedom provides a new and important nuance to the existing literature. It highlights the importance of preserving a sufficient degree of freedom for the therapist's mind to be able roam into a rich fantasy life within a therapeutic intervention.

Furthermore, therapists drew on Winnicott's notions (1971) of 'play' and 'transitional space' to describe the way in which the therapist's reverie could lead to the unfolding of a space between therapist and patient in which meaning could be played with. This enhanced the patient's capacity to play. The opportunity for a parallel process of play between supervisor and supervisee was felt to free-up clinical thinking and to enrich the quality of supervision. This supports Thomas's (2005) argument for the importance of play and creativity in analytic supervision. It leads to the specific implication that therapists' could be encouraged to bring and have reveries to and within supervision, as suggested by Cwik (2006).

The therapist's reverie was commonly understood in this study to arise within a relational matrix in which the inner worlds of therapist and patient meet each other. This view of the intersubjective operation of reveries accords with the psychoanalytic 
literature on the therapist's reverie (Vapenstad, 2014; Cwik, 2011; Cooper, 2008; Ferro, 2009; Mathew, 2005; Ogden, 1994). Participants' sense that their reveries are evoked by unconscious communication from their patient also fits with broader accounts of countertransference that stress intersubjectivity (Maroda 1991; Stolorow, 1992). It was not clear in the study, however, what exactly participants felt the mechanism for this unconscious communication was: whether it could be projective identification, for instance, along the lines of the Bionian model, or something else.

Reveries were felt to operate in an attuned, relational way, while the content of the reveries are also often felt to be concerned with relationships. Therapists often felt that they learned more about the patient's internal object relations and attachment styles from their reveries, and that this could also facilitate therapeutic change. These therapeutic benefits could be linked to the notion of enhanced capacity for symbol formation: being able to 'dream up' - to symbolize - emotional experience, which would accord with Ferro's theory (2009) that the 'reverie activity' of the therapist stimulates that of the patient and leads to growth of mind.

\section{Clinical Implications}

As outlined, the therapist's reveries were felt to potentiate a number of therapeutic benefits. There follows significant implications for clinical technique. Firstly, therapists could be encouraged to bring an attitude of permissiveness and curiosity towards their reveries when they arise. Secondly, it is important for therapists to use their own reflection and supervision to disentangle what belongs to whom in the reverie. As Cwik (2011, p. 17) notes with regards to reverie, 'precisely because of its unconscious nature, one can never know how much of one's own material is in the 
mix'. Lastly, as participants described, the processing of reveries may lead to a shift in the therapist's approach to the patient, if something new is learned. This might affect clinical decisions, especially if the reverie is shared in supervision. There is therefore an important role for the supervisor to attend to the therapist's reveries seriously, and to assist with processing them. Taken together, these implications for clinical technique suggest that the therapist's use of his/her own reverie can be regarded as a specific skill to be cultivated.

\section{Directions for Future Research}

A central finding of this study was the importance therapists attributed to mental freedom and the capacity for reverie in their work. A further key area for future research would be the conditions for mental freedom in therapeutic work, and the role that psychotherapists feel it plays.

\section{Limitations}

Limitations of the study include the small sample size without full 'theoretical sampling', due to the time limitations of the study. However, memos were made after each interview detailing the researcher's reflections about the interview, and these were used to help shape recruitment and interview questions. The importance of theoretical sampling in grounded theory research has been questioned more recently Charmaz (2014, p. 15). However, a next step for a further study could entail following up the initial purposive sampling with theoretical sampling to further pursue aspects of the emergent theory. 
Lastly, this study was designed within a psychodynamic framework. It would be interesting to explore in further research what forms and functions reverie might take in other therapeutic modalities.

\section{References}

Andrews-Hanna, J, Reidler J., Huang, C, Buckner, R. (2010). Evidence for the default network's role in spontaneous cognition. Journal of Neurophysiology, 104, 322-335.

Antrobus, J. (1968). Information theory and stimulus-independent thought. British Journal of Psychology, 59, 423-430.

Benjamin, J. (1998). The shadow of the other: intersubjectivity and gender in psychoanalysis. New York: Routledge.

Benjamin, J. (2004). Beyond doer and done to: an intersubjective view of thirdness. Psychoanalytic Quarterly, 73, 5-46.

Bion, W. (1962b). Learning from experience. London: Tavistock.

Bovensiepen, G. (2002). Symbolic Attitude and Reverie: Problems of Symbolization in Children and Adolescents. Journal of Analytical Psychology, 47, 241-257.

Bond, T. (2004). Ethical guidelines for researching counselling and psychotherapy. 
http://www.bacp.co.uk/admin/structure/files/pdf/e_g.pdf

$(14 / 09 / 14)$

Buckner, R., Andrews-Hanna, J., \& Schacter, D. (2008). The brain's default network: anatomy, function and relevance to disease. Annals of the New York Academy of Sciences, 1124, 1-38.

Charmaz, K. (2006). Constructing grounded theory: a practical guide through qualitative analysis. London: Sage.

Charmaz, K (2014). Constructing grounded theory ( $2^{\text {nd }}$ edition). London: Sage.

Chodorow, N. (2004). The American independent tradition: Loewald, Erikson, and the (possible) rise of intersubjective ego psychology. Psychoanalytic Dialogues, 14, 207-32.

Christoff, K., Ream, J., \& Gabrieli, J., (2004). Neural basis of spontaneous thought processes. Cortex, 40, 623-30.

Christoff, K., Gordon A., Smith R. (2009). The role of spontaneous thought in human cognition. In: O. Vartanian and D. R. Mandel (Eds), Neuroscience of decision making (pp. 259-285). New York: Psychology Press.

Cooper, S. (2010). Privacy, reverie and the analyst's ethical imagination. International Forum of Psychoanalysis, 77, 1045-1073. 
Cwik, A.J. (2006). The Art of the Tincture: Analytical Supervision. Journal of Analytical Psychology, 51, 209-225.

Cwik, A (2011). Associative dreaming: reverie and active imagination. Journal of Analytical Psychology, 56, 14-36.

Ferro, A. (2009). Mind works: technique and creativity in psychoanalysis. London: Routledge.

Freud, S. (1923a) Two encyclopedia articles. Standard Edition, 18., pp. 235-263. London: Hogarth, 1955.

Jung, C. G (1925). In: G. McGuire (Ed.) Analytical Psychology: Notes of the Seminar Given in 1925 by Carl Gustav Jung. Princeton: Princeton University Press. 1991.

Maroda, K. (1991). The Power of Countertransference: Innovations in Analytic Technique. London: Routledge.

Mathew, M. (2005). Reverie: Between Thought and Prayer. Journal of Analytical Psychology. 50, 383-93.

McGown, L. (2015). A qualitative study of the therapist's spontaneous mental imagery and its impact on therapeutic process. Counselling and Psychotherapy Research. 15 (2), 128-136. 
Ogden, T. (1994) The analytic third: working with intersubjective clinical facts. International Journal of Psychoanalysis, 75, 3-19.

Ogden, T. (1997). Reverie and interpretation: sensing something human. London: Karnac.

Ogden, T. (2002). Conversations at the frontier of dreaming. London: Karnac.

Ogden, T. (2004). The analytic third: implications for psychoanalytic theory and technique. Psychoanalytic Quarterly, 23, 167-95.

Parsons, M. (2014). Living psychoanalysis: from theory to experience. London: Routledge.

Renik, O. (1993). Analytic interaction: conceptualizing technique in light of the analyst's irreducible subjectivity. Psychoanalytic Quarterly, 62, 553-571.

Stevens, A. (1990) On Jung. London: Routledge.

Stolorow \& Atwood (1992). Contexts of being: the intersubjective foundations of psychological life. Hillsdale, NJ: The Analytic Press.

Thomas, M. (2005). Through the looking glass: creativity in supervision. In: C. Driver \& E. Martin (Eds), Supervision and the analytic attitude. London: Whurr, pp. 115- 
129.

Vapenstad, E (2014). On the Psychoanalyst's Reverie: From Bion to Bach.

International Forum of Psychoanalysis, 23, 161-170.

Vaslamatzis, G. (1999). On the therapist's reverie and containing function.

Psychoanalytic Quarterly, 58, 431-440.

Winnicott D. (1971). Playing and reality. New York: Basic Books.

Winnicott D. (1960). The theory of the parent-infant relationship. International Journal of Psychoanalysis, 41, 585-595.

Yardley, L. (2000). Dilemmas in qualitative health research. Psychology and Health, $15,215-228$. 